\title{
A novel region selection approach of SVPWM for a three-level NPC inverter used in electric vehicle
}

\author{
Debanjan Roy, Sanatan Kumar, Madhu Singh \\ Departement of Electrical Engineering, National Institute of Technology, India
}

\begin{tabular}{|c|c|}
\hline Article Info & ABSTRACT \\
\hline Article history: & \multirow{10}{*}{$\begin{array}{l}\text { This paper confers an investigation of a space vector modulation based } \\
\text { control strategy of induction motor using a three-level inverter for electric } \\
\text { vehicle application. The proposed controller uses a simple v/f control with a } \\
\text { novel SVPWM technique. A new method for region selection of SVPWM } \\
\text { for a multilevel inverter is implemented for the closed-loop system. } \\
\text { Previously the region selection procedure was not considered by most of the } \\
\text { researcher in the literature for developing the PWM algorithm. This approach } \\
\text { is based on some algebraic equations. The remarkable point here is that it is } \\
\text { identical to all the remaining sectors. Hence calculation complexity reduces } \\
\text { by making it a simpler implementation. This method can be applied to any } \\
\text { number of levels. The potency of the proposed controller is validated through } \\
\text { the MATLAB/SIMULINK environment. The performance of the overall } \\
\text { system is inspected through transient and steady-state analysis. The neutral } \\
\text { point balance of the } 3 \mathrm{~L} \text { NPC inverter is established by adopting proper } \\
\text { switching sequences. }\end{array}$} \\
\hline Received Mar 4, 2019 & \\
\hline Revised Apr 14, 2019 & \\
\hline Accepted Jun 22, 2019 & \\
\hline Keywords: & \\
\hline Electric Vehicle(EV) & \\
\hline Fixed V/F Control & \\
\hline Space Vector Pulse width & \\
\hline Modulation (SVPWM) & \\
\hline Three-level(3L) Inverter & \\
\hline
\end{tabular}

Copyright (C) 2019 Institute of Advanced Engineering and Science. All rights reserved.

\section{Corresponding Author:}

Debanjan Roy,

Departement of Electrical Engineering,

National National Institute of Technology,

Jamshedpur, Jharkhand-831014, India

Email: debanjanroy88@gmail.com

\section{INTRODUCTION}

Due to a limited resource for oil and to reduce the air pollution, electric vehicles emerged as an alternate and reliable solution for the transport industry. Selection of traction motor plays an important role in the electric propulsion system. Depending on various performance characteristics [1] different traction motors are graded in the scale of five. IM and PMSM are the best candidates for traction applications as it has low cost, mature technology and less maintenance [2, 3]. A detailed comparison between traction motor drives are compared in [4] at same vehicle specifications and dimensions. Though PMSM is advantageous due to high power density, less loss and high efficiency, they are restricted due to less availability of rareearth magnets and higher cost [5].

To control the voltage and frequency voltage source inverters are preferred over current source inverters for its fast dynamic response because no-line inductor is used as in the case of CSI. Depending on the pole voltage, inverters are categorized as two level and above two level i.e. multilevel inverters. In case of two-level inverter higher blocking voltage, frequency, switching and conduction losses are extremely high. These losses are dissipated by a heat sink. For dissipating this large amount of power the requirement of a heat sink and cost of cooling system will increase, which will increase the space requirement as well. Hence, the overall size of the system will increase which is not a good practice for traction drives or electric vehicles. Here, multilevel inverters come into play as a solution to this problem. Mainly because it helps to lower the blocking voltage per device which reduces the losses compared to two-level inverter [6-9]. Though vector control is best suited for traction application [6], the fixed $\mathrm{V} / \mathrm{F}$ control is performed in this paper for low cost 
and simple implementation with proposed SVPWM technique as vector control method is more complex in comparison with $\mathrm{V} / \mathrm{F}$ control. A new algorithm for neutral point balancing was reported in [10]. In that paper, Mamdani's fuzzy logic controller based control scheme is presented to improve overall system performance for a $3 \mathrm{~L}$ inverter. A comparison is investigated with and without the neutral point balancing algorithm. A novel technique for region identification of SVPWM for a 3L inverter is introduced and implemented in $[11,12]$ under open loop operation of an induction motor. A simplified SVPWM algorithm is implemented further in [13] where seven segment sequence is implemented for 3L inverter [12] and a detailed comparison is investigated with switching sequence where all the redundant states were used. Proper switching sequences in SVPWM technique plays a crucial part for neutral point balance in multilevel inverter without introducing any extra controller.[14] presents the modelling of an electric vehicle (EV) supported by induction motor and 3L NPC/diode clamped inverter. A fixed $\mathrm{V} / \mathrm{Hz}$ control strategy was used in that paper while the inverter is gated by a Sinusoidal Pulse Width Modulation. Here, a closed loop fixed V/F control is achieved with the novel region selection approach and effectiveness of the proposed controller is investigated through steadystate and transient responses of the induction motor.

The paper consists four different sections. Section two addresses the control structure used for controlling the traction motor. This section has subsection which discusses the proposed SVPWM algorithm which employes novel region identification approach whereas simulation results are shown in section three. Finally, the paper presents a significant concluding observation in section four.

\section{CONTROL STRUCTURE}

In this paper, an induction motor is controlled by a PWM multilevel inverter. An inverter is fed by a dc supply which is converted by a three phase ac rectifier. Here, a fixed V/F strategy is used for controlling the traction motor. Speed controller comprises of a PI controller which generates slip compensation as explained in (1) and then gets summed up with measured rotor speed. Next that signal is converted to frequency to produce commanded stator voltage.

$$
\left(w_{r}^{*}-w_{r}\right)\left(k_{p}+\frac{k_{i}}{s}\right)
$$

PI-controller is tuned using Ziegler-Nichols method where $\mathrm{K}_{\mathrm{p}}$ and $\mathrm{K}_{\mathrm{i}}$ values are obtained at rated load condition [11]. At first, the $\mathrm{Ki}$ is set to zero and $\mathrm{K}_{\mathrm{p}}$ is gradually increased to its ultimate gain $\mathrm{K}_{\mathrm{p}}{ }^{*}$ at which the control loop output oscillates with a constant amplitude. (Tu), the oscillation period and $\mathrm{K}_{\mathrm{p}}$ are used to find out the proportional and integral gains based on the type of the controller. Therefore, the proportional and integral gains $\left(\mathrm{k}_{\mathrm{p}}\right.$ and $\mathrm{k}_{\mathrm{i}}$ ) for particular PI-controller (speed controller) are found $0.45 \mathrm{ku}$ and $1.25\left(\mathrm{~K}_{\mathrm{p}} / \mathrm{T}_{\mathrm{u}}\right)$, respectively.

The overall system implementation is depicted in the figure below. Then derived voltage and frequency from the fixed V/F controller is fed to SVPWM block for generation of gate pulses for 3L NPC inverter as depicted in Figure 1.

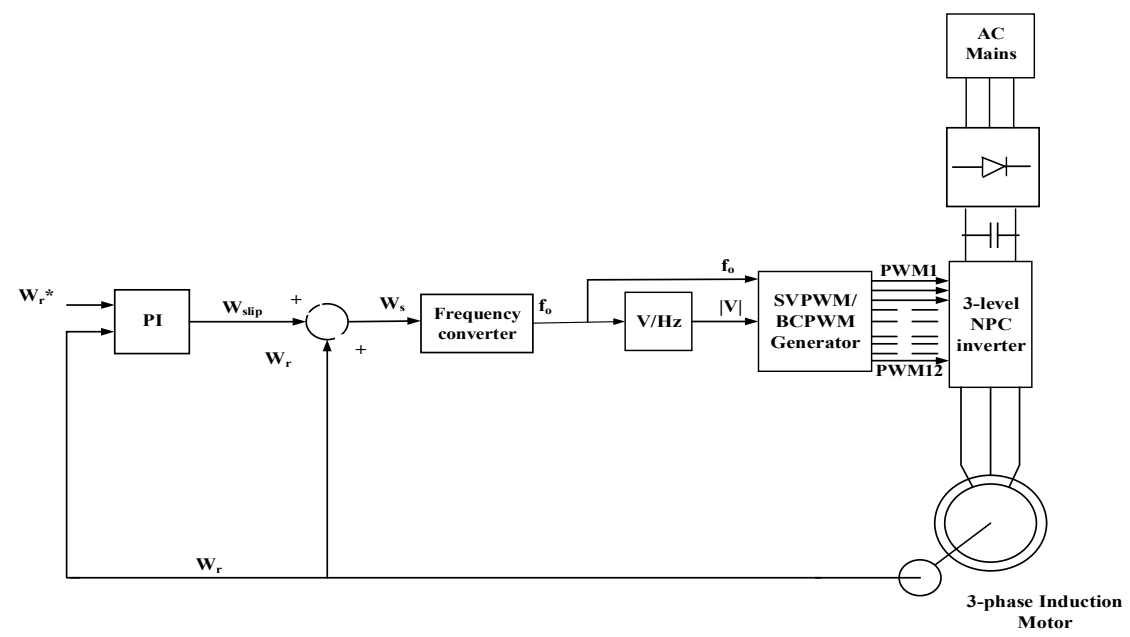

Figure 1. A 3-ph induction motor $\mathrm{V} / \mathrm{Hz}$ drive implementation

Int J Pow Elec \& Dri Syst Vol. 10, No. 4, Dec 2019 : 1705 - 1713 


\section{SVPWM TECHNIQUE FOR 3L INVERTER}

Implementation of SVPWM technique for a multilevel inverter is more complex than a two-level inverter. So, it requires a different approach to deal with it. Mapping based concept for MLI is very popular and presented in [15]. A concept of reverse mapping is also presented in [16] for a five-level and a sevenlevel NPC inverter. MLI topology deal with a number of redundant states which represent the same space vector. For a $3 \mathrm{~L}$ inverter, among 27 space vectors, there are six numbers of the large vector, six numbers of the medium, twelve numbers of short vectors and three numbers of zero/null vectors which form a hexagonal structure as shown in the Figure 2. Each sector has four regions. After region identification, the reference vector is generated by employing nearest three space vectors. Hence, region identification has an influential effect on pulse generation. There are very few publications are available on region identification in the literature. A novel region identification method is introduced in $[11,12]$. Each sector has four regions. After region identification, the reference vector is generated by employing nearest three space vectors. Hence, region identification has an influential effect on pulse generation.A detailed analysis has been performed in different modulation index. In this paper, this method is further implemented for closed-loop control for vehicular application. The method is discussed in detail in the coming section.

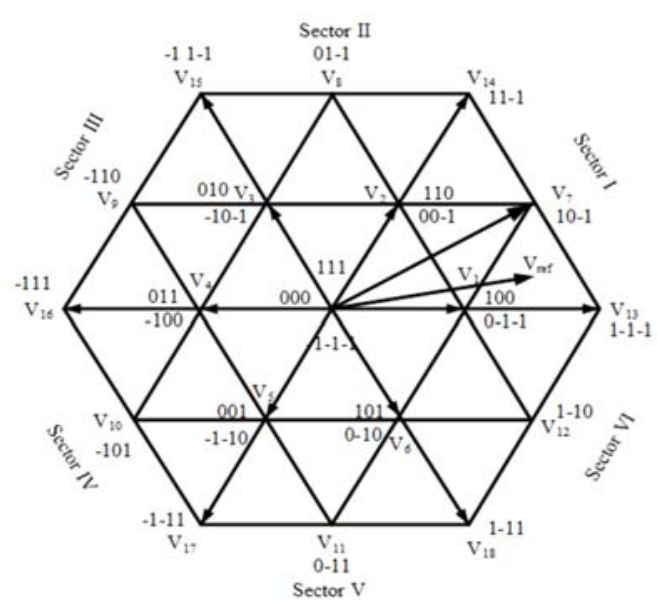

Figure 2. Hexagonal space vector representation of a $3 \mathrm{~L}$ inverter

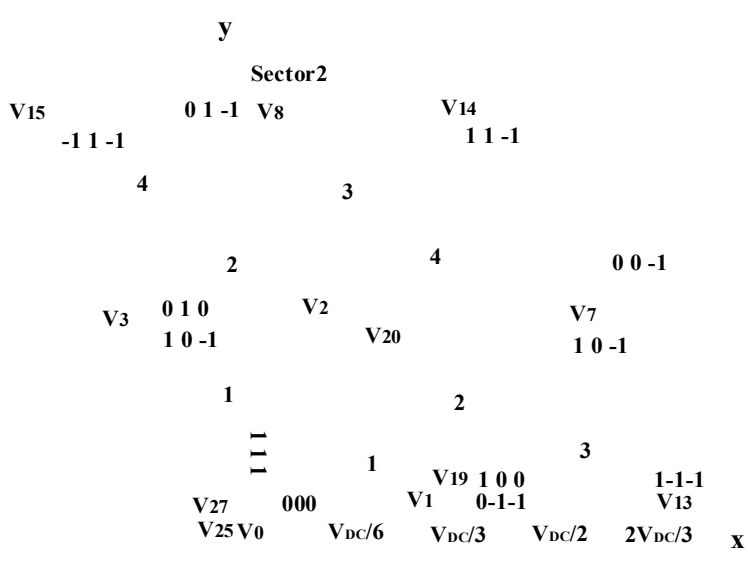

Figure 3. Representation of regions for sector 1 in $\mathrm{x}-\mathrm{y}$ plane

\subsection{Proposed region identification method}

A new method for region identification, based on algebraic equations to locate the position of the $\mathrm{V}_{\text {ref }}$ is presented in this section. Figure 3 depicts two successive sectors (sector 1 and sector 2) and its corresponding regions of a three-level inverter. All the six sectors of the hexagon are symmetry in nature. Hence, the method of region identification for a sector can easily be applied to other sectors. The null vectors are located at the origin of the space vector diagram. Coordinates of other vectors in that sector can be acquired from a 2-dimensional $\mathrm{x}-\mathrm{y}$ plane as illustrated in Figure 3. The $\mathrm{x}$ component of the reference space vector $\left(\mathrm{x}_{1}\right)$ is in phase with the starting vector in that sector and $\mathrm{y}$ component is perpendicular to that $\mathrm{x}$ component. Theta $(\theta)$ represents the angle between the starting and the reference vector. The coordinates of above-mentioned space vectors are given in the Table 1 .

The method is based on mainly two algebraic equations. Both represent the equation of a straight line. First one can be obtained by joining two points i.e. coordinates of V1 and V2. Similarly second straight line can be acquired by joining V1 and V7. Both the equations are written as (2) and (3)

$$
\begin{aligned}
& y_{11}=-\sqrt{3}\left(x-\frac{V_{D C}}{3}\right) \\
& y_{22}=\sqrt{3}\left(x-\frac{V_{D C}}{3}\right)
\end{aligned}
$$


Table 1. The coordinate of individual space vectors in $\mathrm{x}-\mathrm{y}$ plane for sector 1

\begin{tabular}{ccc}
\hline Space Vector & Category & Coordinate $(\mathrm{X}, \mathrm{Y})$ \\
\hline $\mathrm{V}_{25}, \mathrm{~V}_{26}, \mathrm{~V}_{27}$ & null & $(0,0)$ \\
$\mathrm{V}_{1}, \mathrm{~V}_{19}$ & Short & $\left(\frac{V_{D C}}{3,0}\right)$ \\
$\mathrm{V}_{13}$ & Large & $\left(\frac{2 V_{D C}}{3,0}\right)$ \\
$\mathrm{V}_{7}$ & Medium & $\left(\frac{V_{D C}}{2}, \frac{\sqrt{3 V_{D C}}}{6}\right)$ \\
$\mathrm{V}_{14}$ & Large & $\left(\frac{V_{D C}}{3}, \frac{\sqrt{3 V_{D C}}}{3}\right)$ \\
$\mathrm{V}_{2}, \mathrm{~V}_{20}$ & Short & $\left(\frac{V_{D C}}{6}, \frac{\sqrt{3 V_{D C}}}{6}\right)$ \\
\hline
\end{tabular}

The reference vector $V_{\text {ref }}$ has two components

$$
\begin{aligned}
& x_{1}=\left|V_{r e f}\right| \operatorname{Cos} \theta \\
& y_{1}=\left|V_{r e f}\right| \operatorname{Sin} \theta
\end{aligned}
$$

Now, by inserting the value of $x_{1}$ in equation (2) and (3), the values for $y_{11}$ and $y_{22}$ can be obtained as given below-

$$
\begin{aligned}
& y_{11}=-\sqrt{3}\left(x_{1}-\frac{V_{D C}}{3}\right) \\
& y_{22}=\sqrt{3}\left(x_{1}-\frac{V_{D C}}{3}\right)
\end{aligned}
$$

The (5), (6), (7) and $\mathrm{x}-\mathrm{y}$ component of $\mathrm{V}_{\text {ref }}$ are used to identify the regions based on some criteria. The criteria for region identification are formulated in Table 2. Due to symmetric nature between all the sectors, the method remains the same as sector 1 except the $x-y$ coordinate is shifted by $60^{\circ}$.

Table 2. Criteria for region identification in any sector

\begin{tabular}{c}
\hline Region \\
\hline $1+x_{1} \leq V_{D C} / 6$ and $0 \leq \theta \leq 60^{\circ}$ \\
Or \\
$V_{D C} / 6<x_{1}$ and $y_{1} \leq y_{11}$ \\
$V_{D C} / 6<x_{1}$ and $y_{11}<y_{1} \leq \sqrt{3} V_{D C} / 6$ \\
Or \\
$V_{D C} / 2>x_{1}$ and $y_{22}<y_{1} \leq \sqrt{3} V_{D C} / 6$ \\
$V_{D C} / 2<x_{1}$ and $y_{1} \leq y_{22}$ \\
Or \\
$V_{D C} / 2<x_{1}$ and $0 \leq \theta \leq 30^{\circ}$ \\
4 \\
If above three conditions are not satisfied then select \\
region 4
\end{tabular}

\subsection{Vector sequence and Dwell time calculations}

The vector sequence of any region should maintain the following criteria; a) In any sequence, changeover between states allows the only one switching i.e. a transition from 1 to -1 or vice-versa is prohibited. b) Terminal state of any current sample should be the initial state of the upcoming sample. The different sequences for different regions in sector 1 are tabularized in Table 3.

Int J Pow Elec \& Dri Syst Vol. 10, No. 4, Dec 2019 : 1705 - 1713 
Table 3. Vector sequences of regions $(1,2,3,4)$ in sector 1

\begin{tabular}{cc}
\hline Region & Vector Sequence \\
\hline 1 & $V_{19} \leftrightarrow V_{20} \leftrightarrow V_{26} \leftrightarrow V_{I}$ \\
& $(0-1-1)(00-1)(000)(100)$ \\
& $V_{19} \leftrightarrow V_{20} \leftrightarrow V_{7} \leftrightarrow V_{I}$ \\
3 & $(0-1-1)(00-1)(10-1)(100)$ \\
& $V_{19} \leftrightarrow V_{13} \leftrightarrow V_{7} \leftrightarrow V_{I}$ \\
4 & $(0-1-1)(1-1-1)(10-1)(100)$ \\
& $V_{20} \leftrightarrow V_{7} \leftrightarrow V_{14} \leftrightarrow V_{2}$ \\
& $(00-1)(10-1)(11-1)(110)$ \\
\hline
\end{tabular}

The space vector diagram that is shown in Figure 2 can be used to calculate the time for each sector (I to VI). Each sector has four regions (1 to 4), as shown in Figure 3, with the switching states of all vectors. The sum of the voltage multiplied by the interval of chosen space vector equals the product of the reference voltage $V_{\text {ref }}$ and sampling period $T_{s}$. To illustrate, when reference voltage is located in region 2 of sector I then the nearest vectors to reference voltage are $V_{1}, V_{7}$, and $V_{2}$ as shown in Figure 3 and 4 , and the next equations explain the relationship between times and voltages.

The volt-sec balance equation for region 2 is

$$
V_{1}^{*} T_{a}+V_{7} * T_{b}+V_{2} * T_{c}=V_{r e f} * T_{s}
$$

Where $T_{a}, T_{b}$ and $T_{c}$ are the times for $V_{1}, V_{7}$, and $V_{2}$ respectively.

By putting the values of $V_{1}, V_{7}$, and $V_{2}$ respectively we get,

$$
\begin{aligned}
& \frac{V_{d}}{3} * T_{a}+\frac{V_{d}}{3}\left(\cos 60^{\circ}+\sin 60^{\circ}\right) * T_{b}+ \\
& \frac{\sqrt{3} V_{d}}{3}\left(\cos 30^{\circ}+\sin 30^{\circ}\right) * T_{c}=V_{r e f} * T_{s} \\
& T_{a}+T_{b}+T_{c}=T_{s}
\end{aligned}
$$

From equation (9) real part and imaginary part can be determined and using equation (8), (9) and

\begin{tabular}{|c|c|c|}
\hline Region & Space Vectors & Dwell Time/ Switching Time \\
\hline \multirow{6}{*}{1} & $V_{1}, V_{19}$ & $T_{a}=T_{S}\left\{2 m \operatorname{Sin}\left(\frac{\pi}{3}-\theta\right)\right\}$ \\
\hline & $V_{26}$ & $T_{b}=T_{S}\left\{1-2 m \operatorname{Sin}\left(\frac{\pi}{3}-\theta\right)\right\}$ \\
\hline & $V_{20}$ & $T_{c}=T_{S}\{2 m \operatorname{Sin} \theta\}$ \\
\hline & $V_{1}, V_{19}$ & $T_{a}=T_{S}\{1-2 m \operatorname{Sin} \theta\}$ \\
\hline & $V_{7}$ & $T_{b}=T_{S}\left\{2 m \operatorname{Sin}\left(\frac{\pi}{3}+\theta\right)-1\right\}$ \\
\hline & $V_{20}$ & $T_{c}=T_{S}\left\{1-2 m \operatorname{Sin}\left(\frac{\pi}{3}-\theta\right)\right\}$ \\
\hline \multirow{3}{*}{3} & $V_{1}, V_{19}$ & $T_{a}=T_{S}\left\{2-2 m \operatorname{Sin}\left(\frac{\pi}{3}+\theta\right)\right\}$ \\
\hline & $V_{7}$ & $T_{b}=2 T_{S} m \operatorname{Sin} \theta$ \\
\hline & $V_{13}$ & $T_{c}=T_{S}\left\{2 m \operatorname{Sin}\left(\frac{\pi}{3}-\theta\right)-1\right\}$ \\
\hline \multirow{3}{*}{4} & $V_{14}$ & $T_{a}=T_{S}\{2 m \operatorname{Sin} \theta-1\}$ \\
\hline & $V_{7}$ & $T_{b}=T_{S}\left\{2 m \operatorname{Sin}\left(\frac{\pi}{3}-\theta\right)\right\}$ \\
\hline & $V_{2}, V_{20}$ & $T_{c}=T_{S}\left\{2-2 m \operatorname{Sin}\left(\frac{\pi}{3}+\theta\right)\right\}$ \\
\hline
\end{tabular}
(10) we obtained the required dwell timings for the voltage vectors in region 2. Similarly, dwell timings for different regions are calculated as shown in Table 4.

Table 4. Switching times for sector 1

Where, $T_{s}$ is the sampling time. 


$$
T_{s}=T_{a}+T_{b}+T_{c}
$$

Modulation Index $(\mathrm{MI})=\sqrt{3} *\left(V_{r e f} / V_{D C}\right)$

Figure 4 shows seven segment sequences of regions in sector 1. As mentioned earlier, only a switch is operated in every state changeover. The vector sequences for other regions in sector 1 are shown in Table 3. The dwelling times for the vectors of sector 1 are arranged in Table 4.

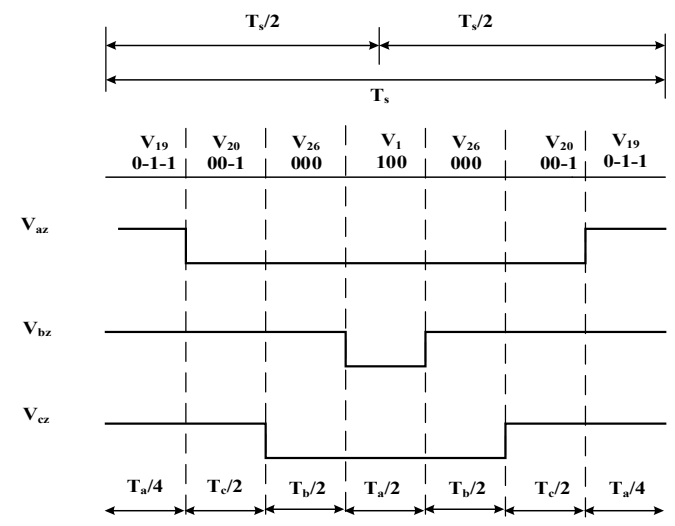

(a)
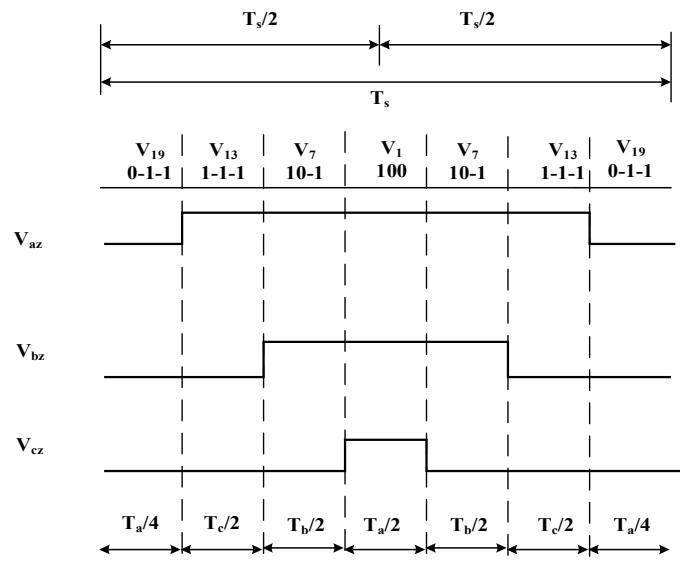

(c)

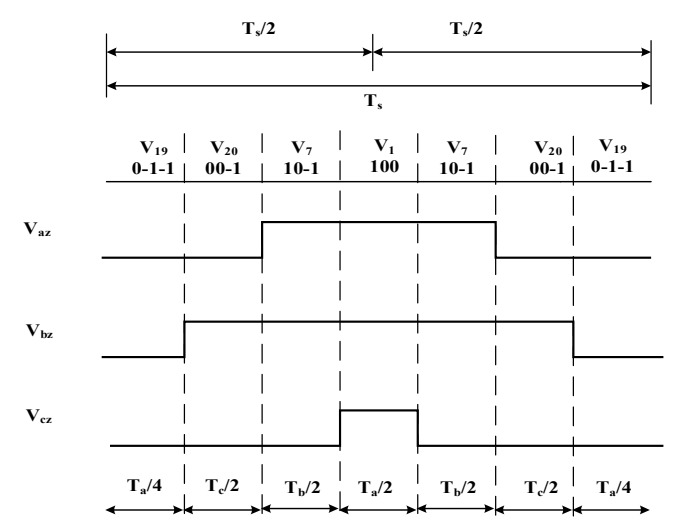

(b)
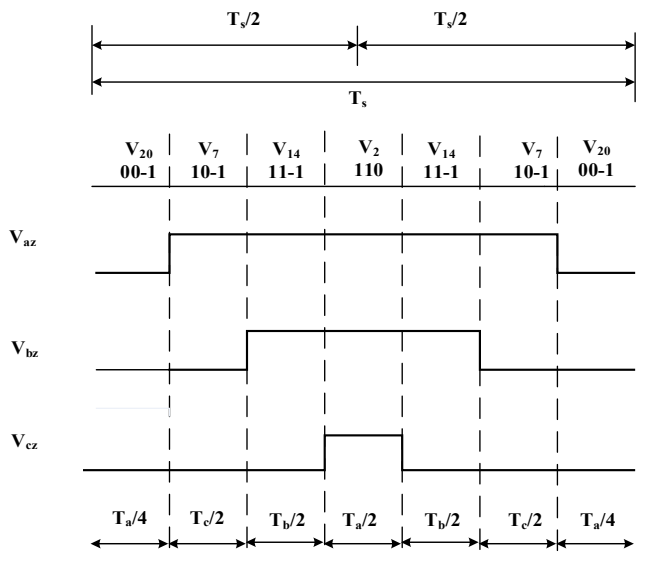

(d)

Figure 4. Seven segment switching sequences for (a) region 1, (b) region 2, (c) region 3, (d) region 4 of sector 1

\section{SIMULATION OUTCOMES}

In this section, the proposed SVPWM algorithm is examined through the simulation results. The control scheme has already depicted ealier in the Figure 1. The neutral point balance for 3L NPC inverter is also investigated. The analysis of the overall system has been performed under transient and steady-state conditions. The overall simulated period is divided into three subsections i.e. speed response, torque response and steady state response. Speed response defines a change in speed whereas a change in torque represents torque response. The parameters used are jotted down below.

DC bus voltage, $\mathrm{V}_{\mathrm{DC}}=353 \mathrm{~V}$

Nominal Power $=4 \mathrm{KW}$.

Rated Speed $=1430$ r.p.m.

$\mathrm{R}_{\mathrm{s}}=1.405 \Omega, \mathrm{R}_{\mathrm{r}}=1.395 \Omega, \mathrm{L}_{\mathrm{m}}=0.1722 \mathrm{H}$ and $\mathrm{L}_{\mathrm{ls}}=\mathrm{L}_{\mathrm{lr}}=0.005839 \mathrm{H}$.

Switching frequency, $\mathrm{f}_{\mathrm{sw}}=5 \mathrm{kHz}$. 


\subsection{Speed response}

The system is initially operated with a reference speed of 700 r.p.m and a reference torque of 10 $\mathrm{Nm}$. At $\mathrm{t}=4 \mathrm{~s}$ reference, speed is increased from 700 to 1000 r.p.m keeping reference torque constant at $10 \mathrm{~N}$ $\mathrm{m}$ as shown in Figure 5(a). The system deportment is depicted during the speed change in Figure 5(a). The mentionable point is that the rotor speed follows its reference value very accurately and verifies the effectiveness of the suggested SVPWM algorithm. In Figure 5(b) electromagnetic torque ripple shown as 2.4 $\mathrm{Nm}$. Neutral point balancing of NPC is also investigated. During the speed response capacitors voltage ripple is shown in Figure 5(c) which is about $6.7 \mathrm{~V}$ in transient and under steady state, ripple comes down to $5.8 \mathrm{~V}$. The proposed algorithm keeps the dc bus voltage balanced at a particular tolerance level of $5 \%$ that of the total Dc bus voltage shown in Figure 5(c).

\subsection{Torque response}

At $\mathrm{t}=9 \mathrm{~s}$ reference, torque is increased from $10 \mathrm{Nm}$ to 15 keeping speed constant at 1000 r.p.m. Figure 6(a) shows rotor speed behaviour in torque response. During this transition, the speed drops from 1000r.p.m. to $956.67 \mathrm{rpm}$ and settles it down within 0.25 seconds. Figure $6(\mathrm{~b})$ shows the electromagnetic torque behaviour of the system. The electromagnetic torque ripple is restricted to $2.8 \mathrm{Nm}$. under steady state. From Figure 6(c) the capacitors Voltage ripples are investigated at $\mathrm{t}=9 \mathrm{~s}$ as well as in a steady state.

\subsection{Steady state response}

In steady state, the rotor rotates at $1000 \mathrm{rpm}$. Figure 7(a) and Figure 8(a) shows the stator current and stator voltage respectively. Figure 7(b) illustrates the FFT analysis of the stator current. The \%THD of the line current at $35.7 \mathrm{~Hz}$ is calculated in Figure 7(b). The inverter switching frequency is maintained at 5 $\mathrm{KHz}$. The harmonics seem as sidebands and concentrated at the switching frequency and its multiples i.e. surrounding $5 \mathrm{KHz}, 10 \mathrm{KHz}, 15 \mathrm{KHz}$ etc. Figure 8(a) depicts phase to phase voltage of the $3 \mathrm{~L}$ inverter which is fed to the stator of the induction motor and Figure 8(b) showss the FFT analysis of phase to phase voltage.

The effect of load variation at constant speed (frequency) on different power quality indices are studied. Variation in line-line voltage, current, \%THD of line voltage and current are also studied for different load demand i.e. $25 \%, 50 \%, 75 \%$ and $100 \%$ of rated load. Effect of load variation on dc link voltage ripple and torque ripple is tabulated in Table 5. It is seen from the Table 5 that stator current THD is below $5 \%$ which obeys IEEE 519 standard. It can be seen from the Table 5 that as load increases stator current increases but dc link voltage ripple also increases. Torque ripple decreses as load increases. \%THD of Stator voltage also decreases with increasing load. From these observations, the proposed SVPWM algorithm for EV system has very good power quality performance for varying load.

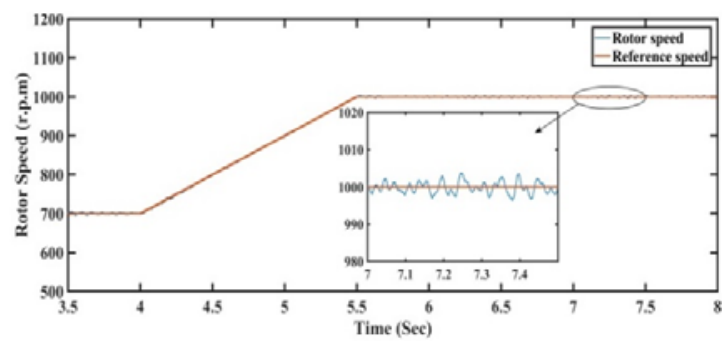

(a)

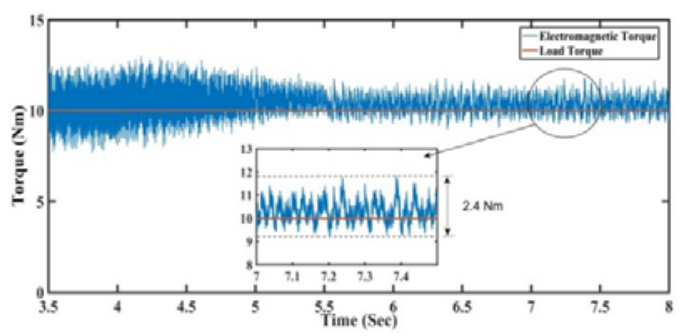

(b)

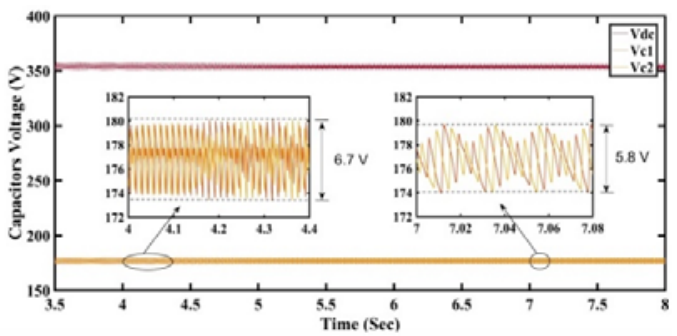

(c)

Figure 5. Speed response: (a) rotor speed, (b) electromagnetic torque, (c) capacitors voltage. 


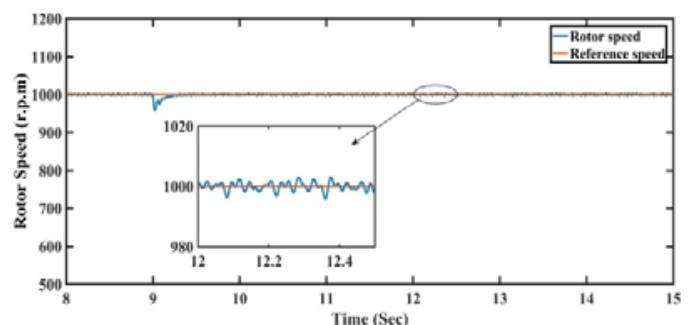

(a)

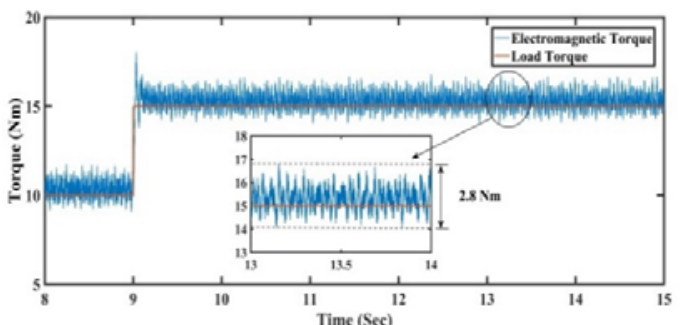

(b)

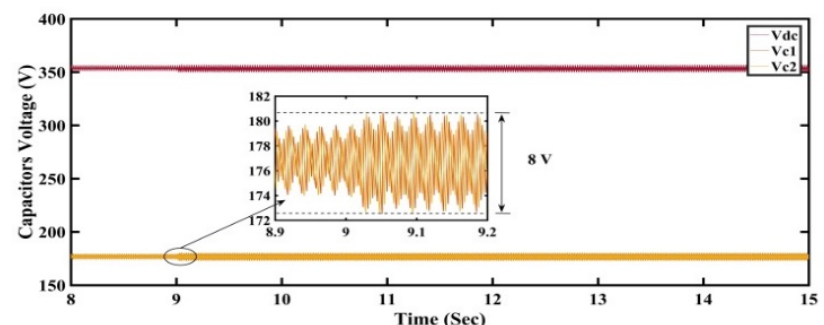

(c)

Figure 6. Torque response: (a) rotor speed, (b) electromagnetic torque, (c) capacitors voltage.

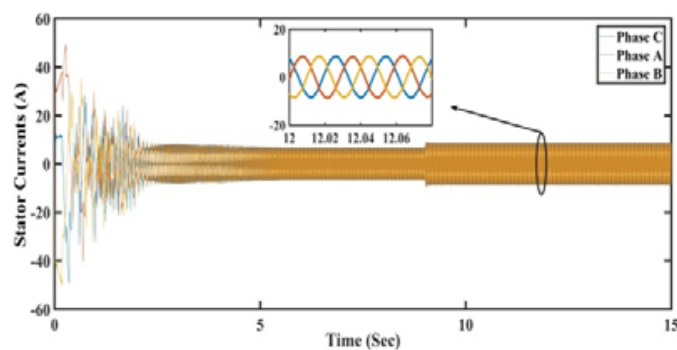

(a)

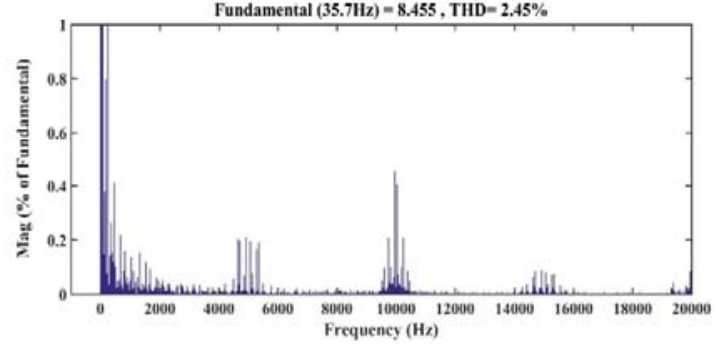

(b)

Figure 7. (a) Stator currents, (b) THD of stator current

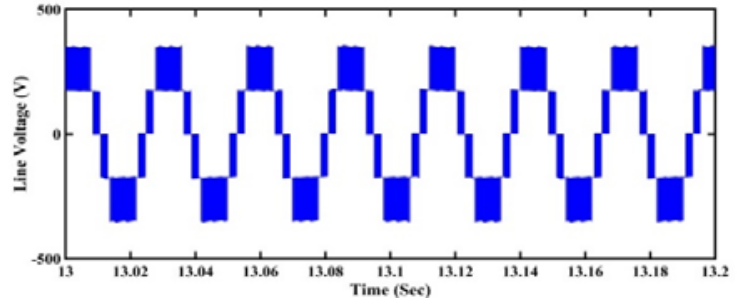

(a)

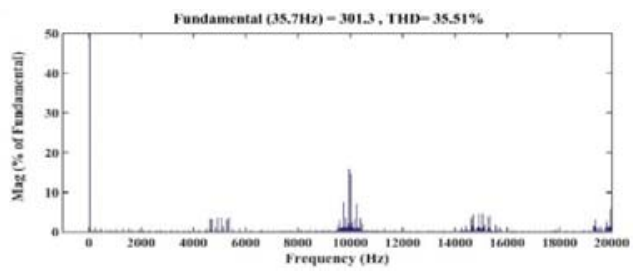

(b)

Figure 8. (a) Lne voltage, (b) THD of line voltage

Table 5. Performance of power quality indices under varying load operation

\begin{tabular}{ccccccc}
\hline Load $(\%)$ & $\begin{array}{c}\text { V(L-L) }(\mathrm{rms}) \\
(\mathrm{V})\end{array}$ & $\begin{array}{c}\mathrm{I}(\mathrm{rms}) \\
(\mathrm{A})\end{array}$ & $\mathrm{V}$ & $\mathrm{I}$ & $\begin{array}{c}\text { \% THD link voltage } \\
\text { ripple }(\mathrm{V})\end{array}$ & $\begin{array}{c}\text { Ripple in torque } \\
(\mathrm{Nm})\end{array}$ \\
\hline 25 & 251.7 & 3.976 & 37.38 & 3.65 & 5.13 & 3 \\
50 & 251.34 & 5.954 & 35.61 & 2.48 & 7 & 3.2 \\
75 & 251.2 & 8.184 & 34.68 & 1.48 & 9.82 & 2.226 \\
100 & 251.13 & 10.9 & 33.57 & 1.61 & 12.395 & 2.53 \\
\hline
\end{tabular}


Table 6. Performance of power quality indices under varying speed (frequency) operation

\begin{tabular}{ccccccc}
\hline $\begin{array}{c}\text { Speed } \\
(\mathrm{rpm})\end{array}$ & $\begin{array}{c}\text { Frequency } \\
(\mathrm{Hz})\end{array}$ & $\begin{array}{c}\mathrm{V} \\
(\mathrm{rms})\end{array}$ & $\mathrm{V}$ & $\mathrm{I}$ & $\begin{array}{c}\text { DC link voltage } \\
\text { ripple }(\mathrm{V})\end{array}$ & $\begin{array}{c}\text { Ripple in torque } \\
(\mathrm{Nm})\end{array}$ \\
\hline 800 & 28.57 & 251.77 & 39.5 & 6.11 & 9 & 4.18 \\
1000 & 35.7 & 251.27 & 35.32 & 1.84 & 7.95 & 2.33 \\
1200 & 42.4 & 251.06 & 25.86 & 2.01 & 8.25 & 3.53 \\
1400 & 49.95 & 250.92 & 24.3 & 3.02 & 6.95 & 2.75 \\
\hline
\end{tabular}

\section{CONCLUSION}

A new method of SVPWM for 3L inverter has been presented for electric vehicle application. A 4 $\mathrm{kW}$ induction motor is considered as traction motor and simulated in the MATLAB/SIMULINK platform. Investigation of speed and torque response of the system validated the effectiveness of the presented scheme. In steady state, the capacitors voltage ripples were also limited to a tolerable value. \%THD of the output voltage and output current of the 3L inverter in the steady state also established the efficacy of the presented SVPWM algorithm. In future, the hardware implementation of this proposed work will be a challenging task.

\section{REFERENCES}

[1] Saqib Jamshed Rind, Yaxing Ren, Yihua Hu, Jibing Wang and Lin Jiang, "Configurations and Control of Traction 4 Motors for Electric Vehicles: A Review”, Chinese Journal of Electrical Engineering, Vol. 3, No. 3, pp. 1-17, 2017.

[2] Soby T. Varghese and K.R. Rajagopa, "Economic and Efficient Induction Motor Controller for Electric Vehicle using Improved Scalar Algorithm", $1^{\text {st }}$ IEEE International Conference on Power Electronics, Intelligent Control and Energy Systems, pp. 1-17, 2016.

[3] Nasser Hashernnia and Behzad Asaei, "Comparative study of using different electric motors in the electric vehicles", $18^{\text {th }}$ International Conference on Electrical Machines, Vilamoura, Portugal, pp. 1-5 , Sept. 2008.

[4] Gianmario Pellegrino, Alfredo Vagati, Barbara Boazzo and Paolo Guglielmi, "Comparison of Induction and PM Synchronous Motor Drives for EV Application Including Design Examples", IEEE Transactions on Industry Applications, Vol. 48, No. 6, pp. 2322-2332, 2012.

[5] P. Xue and J. Lin, "Discussion on the rare earth resources and its development potential of Inner Mongolia of China", in Proc. ICMREE, Shanghai, China, pp. 9-12, 2011.

[6] L. Clotea, A. Forcos, C. Marinescu and M. Georgescu. "Power loss analysis of two-level and three-level neutral point clamped inverters for a wind pump storage system", In Proc. on IEEE 12th Int. Conf. on Optimization of Electrical and Electronic Equipment, Brasov, Romania, pp. 1174-1179, May 2010.

[7] R. Macke, "Multilevel NPC inverter for low-voltage applications", In Proc. IEEE 14th European Conf. on Power Electronics Applications, Birmingham, UK, pp. 1-10, Sept. 2011.

[8] Z. Chen, L. Yuan, and Z. Zhao, "Power losses in 2- and three-level three-phase photovoltaic inverters equipped with IGBT's", in Proc. IEEE 15th Int. Conf. on Electrical Machines and Systems, Sapporo, Japan, pp. 1-6, Oct. 2012.

[9] R. Teichmann and S. Bernet, "A comparison of three-level converter versus two-level converters for low-voltage drives, traction, and utility applications", IEEE Trans. on Industry Applications, Vol. 41, No. 3, pp. 855-865, May 2005.

[10] R. Thomas Nathenas and Georgios Adamidis, "A new approach for SVPWM of a three-level inverter-induction motor fed-neutral point balancing algorithm”, Simulation Modeling Practice and Theory, Vol. 29, pp. 117, 2012.

[11] D Roy, M Singh and T Roy, "A Novel Approach for Space Vector Based PWM Algorithm for Diode Clamped Three level VSI Fed Induction Motor Drive", International Journal of Power Electronics and Drive Systems (IJPEDSO, Vol. 8, No. 4, pp. 1534-1547, 2017.

[12] Debanjan Roy and Tapas Roy, "A new technique to implement conventional as well as advanced Pulse Width Modulation techniques for multi-level inverter", IEEE 6th India International Conference on Power Electronics (IICPE), Kurukshetra, India, pp. 1-6, Aug. 2014.

[13] Debanjan Roy and Madhu Singh, "A simplified space vector pulse width modulation for three phase three-level diode clamped inverter", 1st IEEE International Conference on Smart grids, Power and Advanced Control Engineering (ICSPACE), Bangalore, India, pp. 226-230, Aug. 2017.

[14] Mario A. Gonzalez and Miguel F. Escalante, "Traction System for an EV Based on Induction Motor and 3-Level NPC Inverter Multilevel Converters", 12th IEEE International Power Electronics Congress, San Luis Potosi, Mexico, pp. 2873-77, 2010

[15] Aneesh Mohamed A. S., Anish Gopinath and M. R. Baiju, “A Simple Space Vector PWM Generation Scheme for Any General n-Level Inverter", IEEE Transactions on Industrial Electronics, Vol. 56, pp. 1649-1656, May 2009.

[16] N. Susheela, P. Satish Kumar and S.K.Sharma, "Generalized Algorithm of Reverse Mapping based SVPWM Strategy for Diode Clamped Multilevel Inverters", IEEE Transactions on Industry Applications, DOI 10.1109/TIA.2018.2790906. 